\title{
Anti-Peripheral Nerve Myelin Antibodies in Guillain-Barre Syndrome Bind a Neutral Glycolipid of Peripheral Myelin and Cross-react with Forssman Antigen
}

\author{
C. L. Koski, “ D. K. H. Chou, ${ }^{\ddagger}$ and F. B. Jungalwala \\ ${ }^{*}$ Department of Neurology, University of Maryland School of Medicine, Baltimore, Maryland 21201; ${ }^{\ddagger}$ Department of Biochemistry, \\ E. K. Shriver Center for Mental Retardation Inc., Waltham, Massachusetts 02254
}

\begin{abstract}
During acute-phase illness, serum of patients with GuillainBarre syndrome (GBS) contain complement-fixing antibodies (Ab) to peripheral nerve myelin (PNM). We investigated PNM lipids as putative antigens for these Ab since GBS serum retained significant reactivity to PNM treated with protease. Ab binding to specific lipids was studied with a $\mathrm{Cl}$ fixation and transfer (C1FT) assay using fractions of PNM lipid reincorporated into liposomes as antigen targets or to lipids on HPTLC plates with peroxidase-labeled goat Ab to human IgM. Reactivity was detected to a neutral glycolipid (NGL) of human PNM with a similar number of carbohydrates residues to that of Forssman hapten (Forss). Anti-NGL Ab titers in GBS patients (50-220 U/ml) were significantly elevated over disease and normal controls (0-5 and 0-6 U/ml). We studied possible antigenic cross-reactivity of these $\mathrm{Ab}$ with Forss by first quantitating Ab activity with C1FT assay and liposomes containing Forss. All 12 GBS sera tested showed titers (54-272 U/ml) significantly elevated over 11 disease controls (0-22 U/ml) and 25 normal controls (0-11 U/ml). GBS serum Ab reacted with Forss isolated from dog nerve or sheep erythrocytes on HPTLC plates. Further, absorption of $80-100 \%$ of anti-NGL Ab activity and 17-97\% of anti-PNM Ab activity from eight GBS patient serums was accomplished with liposomes containing Forss but not with control liposomes. In seven GBS patients anti-NGL $A b$ activity represented only a portion of anti-PNM Ab activity. These results suggest that a glycolipid with antigenic cross-reactivity to Forssman hapten may be responsible for some of the anti-PNM Ab activity in GBS.
\end{abstract}

\section{Introduction}

The Guillain-Barre syndrome (GBS) ${ }^{1}$ is a condition in which transient neurologic symptoms are associated with an inflam-

Address reprint requests to Dr. Koski, Department of Neurology, University of Maryland Hospital, 22 South Greene Street, Baltimore, MD 21201.

Received for publication 13 April 1988 and in revised form 21 February 1989.

1. Abbreviations used in this paper: $\mathrm{DGVB}^{2+}$, veronal buffer, $\mathrm{pH} 7.4$, containing $2.5 \%$ dextrose, $0.1 \%$ gelatin, $0.15 \mathrm{mM} \mathrm{CaCl}_{2}$ and $1.0 \mathrm{mM}$ $\mathrm{MgCl}_{2}$; EDTA/VBS, $10 \mathrm{mM}$ EDTA in VBS; GBS, Guillain-Barre Syndrome; $\mathrm{GVB}^{2+}$, VBS with $0.1 \%$ gelatin, $0.15 \mathrm{mM} \mathrm{CaCl}_{2}$ and 1.0 $\mathrm{mM} \mathrm{MgCl}{ }_{2}$; HPTLC, high performance thin-layer chromatography; NGL, neutral glycolipid; PNM, peripheral nerve myelin; VBS, barbital-buffered saline containing $145 \mathrm{mM} \mathrm{NaCl}, 5 \mathrm{mM}$ sodium barbital, pH 7.4.

J. Clin. Invest.

(c) The American Society for Clinical Investigation, Inc.

0021-9738/89/07/0280/08 $\$ 2.00$

Volume 84, July 1989, 280-287 matory demyelination of peripheral nerve in which myelin is the target of immune attack $(1,2)$. Although details of the mechanism of myelin destruction are not known available evidence suggests that humoral factors, such as $\mathrm{Ab}$ and complement are involved. Complement fixing antibodies to peripheral nerve myelin (anti-PNM Ab) can be detected in the serum of GBS patients, and are highest when neurologic symptoms first occur (3-6). Clearance of the IgM isotope of these anti-PNM Ab from serum of GBS patients correlates well with the changing clinical status $(5,6)$. In addition, the $A b$ activity in serum of patients correlates with the appearance of the activated products of the terminal complement cascade in serum, cerebrospinal fluid, and peripheral nerve of GBS patients (7-9). Plasmapheresis during the first two weeks of disease shortens the clinical course (10-12).

Both protein and lipid antigens in PNM are implicated in the production of human and experimental demyelinating neuropathies by $\mathrm{Ab}$ reactivity. Monoclonal immunoglobulin of some patients with a paraprotein associated demyelinating neuropathy binds a shared carbohydrate determinant of the myelin-associated glycoprotein (MAG) and unusual sulfoglucuronyl glycosphingolipids of PNM (13-16). Serum of these patients demyelinate cat sciatic nerve in the presence of complement (17). $P_{2}$ and galactocerebroside both induce experimental neuritis in rats and rabbits $(18,19)$. $A b$ to $P_{2}$ a basic protein which is not exposed on the myelin surface does not demyelinate explants in vitro (20) while $A b$ to the surface determinant galactocerebroside causes in vivo and vitro demyelination $(21,22)$ and mediates cytoxicity of Schwann cells (23). GBS serum also mediates demyelination in vivo and in vitro (24-26). Despite the success in animal models and human paraprotein-associated neuropathy, no consistent $A b$ reactivity to any of these recognized PNM antigens in GBS is reported $(27,28)$. More recently, IgM and/or IgG from 6 of 21 GBS patients tested showed binding activity to carbohydrate determinants of a series of PNM and CNM gangliosides separated on a thin-layer chromatography plate (29). Although these last findings are of interest, no consistent antigen was found and many of the gangliosides bound were shared by both neural and extraneural tissues.

In this study we have evaluated the nature of the PNM lipids as putative antigens for antibody reactivity in GBS serum. Using complement component $\mathrm{C} 1$ fixation, immunoabsorption and solid-phase assays, we found that all GBS patients' sera studied contained anti-PNM Ab, which bind to a neutral glycolipid of PNM.

\section{Methods}

Collection of clinical material. Serum was collected from patients meeting criteria of the Ad Hoc Committee for GBS (30) during the acute phase of their illness, aliquoted, and stored at $-70^{\circ} \mathrm{C}$. The clinical and humoral characterization of these sera has been previously described $(5,6,9)$. Serum was also obtained from patients with sys- 
temic lupus erythematosus, rheumatoid arthritis, cancer, paraprotein without neuropathy, poliomyelitis, amyotrophic lateral sclerosis, multiple sclerosis, sarcoidosis, alcoholism, diabetes, as well as other toxic and hereditary neuropathies. Control serum was from healthy laboratory workers.

Buffers. Veronal-buffered saline (VBS) pH 7.4, $\mathrm{U}=0.15$, was prepared by diluting a stock solution (31) fivefold with water. $\mathrm{GVB}^{2+}$ was VBS with $0.1 \%$ gelatin, $0.15 \mathrm{mM} \mathrm{CaCl}_{2}$ and $1.0 \mathrm{mM} \mathrm{MgCl}_{2} \mathrm{DGVB}^{2+}$ was veronal buffer, $\mathrm{pH} 7.4, \mathrm{U}=0.07$, containing $2.5 \%$ dextrose, $0.1 \%$ gelatin, $0.15 \mathrm{mM} \mathrm{CaCl}_{2}$, and $1.0 \mathrm{mM} \mathrm{MgCl}$ ). EDTA/VBS was prepared by mixing 9 vol of VBS with 1 vol of 0.1 M EDTA.

Complement and complement components. Guinea pig $\mathrm{C} 2$ was purchased from Diamedix Laboratories (Miami, FL). Human serum depleted of C2 (C2D-HS) was purchased from Cytotech (San Diego, CA). Fresh frozen guinea pig serum diluted 1:40 in EDTA/VBS was used as a source of $\mathrm{C} 3$ and $\mathrm{C} 5$ through $\mathrm{C} 9$.

Detection of $A b$ binding to antigen by $C 1$ fixation. The $\mathrm{Cl}$ fixation and transfer assay was performed as described previously $(5,6)$. Briefly, a fixed amount of PNM, pronase-treated PNM, or liposomes was incubated overnight at $4^{\circ} \mathrm{C}$ with different amounts of human serum diluted in EDTA/VBS to a final volume of $500 \mu$ l. The antigen was washed three times with $1 \mathrm{ml}$ of $\mathrm{GVB}^{2+}$ by centrifugation in a Sorvall microfuge at $4^{\circ} \mathrm{C}$ for 5 or $15 \mathrm{~min}$ at full speed. The pellet was resuspended in $300 \mu$ lof C2D-HS (as a source of excess C1) diluted 400-fold with $\mathrm{GVB}^{2+}$, then incubated for $30 \mathrm{~min}$ at $37^{\circ} \mathrm{C}$. After washing, the antigen slurry, now carrying specific $\mathrm{Ab}$ and $\mathrm{Cl}$ was incubated with sheep erythrocytes carrying anti-Forssman $\mathrm{Ab}, \mathrm{C} 4 \mathrm{~b}$, and $\mathrm{C} 3 \mathrm{~b}$ for 15 min at $30^{\circ} \mathrm{C}$. Incubations were further carried out first with excess guinea pig $\mathrm{C} 2$ then with EDTA-treated guinea pig serum as a source of C3, C5-C9. Lysis of cells was determined spectrophotometrically, and levels of Ab against PNM or specific lipid fractions were calculated as previously described.

Antigen preparation. PNM was isolated on a discontinuous sucrose gradient by the method of Norton from human dorsal and ventral spinal nerve roots obtained at autopsy within $12 \mathrm{~h}$ of death (32). Ab binding was detected by $\mathrm{Cl}$ fixation against native myelin or myelin treated with pronase (Streptococcus greseus; Calbiochem-Behring Corp., La Jolla, CA) in a 20 to 1 protein enzyme (wt/wt) ratio for $2 \mathrm{~h}$ at $37^{\circ} \mathrm{C}$, followed by incubation with $2 \mathrm{mM}$ PMSF and extensive washes. Pronase treatment resulted in loss of greater than $92 \%$ of myelin protein as determined by a modified Lowry assay (33).

Lipid fractions were prepared as previously described from human sciatic nerve (16). Briefly, lipids were extracted overnight at room temperature in chloroform/methanol/water, 1:1:0.1 (vol/vol/vol) followed by chloroform/methanol (2:1). The combined lipid extract, adjusted to have a final solvent proportion of chloroform/methanol 2:1, was partitioned into two phases by addition of $0.2 \mathrm{vol}$ of water and the lower phase was further partitioned into five fractions (designated $\mathrm{fx}$ 1-5) on a Unisil column (Clarkson Chemical Co., Williamsport, PA) by elution with 5 column volumes of chloroform, acetone, acetone:methanol (9:1, vol/vol), and methanol. The upper phase was subjected to a further Folch partition with salt (34). The resultant lower phase was designated as fraction 6 . The upper phase, which contained acidic and some higher neutral glycolipids, was applied to a DEAESephadex A 25 column and eluted with methanol ( $\mathrm{fx} 8$ ) and methanol containing increasing concentrations of ammonium acetate $(0.02$, $0.08,0.2$, and $0.5 \mathrm{M}$ ) designated fractions $9 \mathrm{a}-\mathrm{d}$. Fractions $9 \mathrm{a}-\mathrm{d}$ were desalted by the Bond-Elute method (35). Fraction 8 was further purified over a Unisil column $(5 \mathrm{~g})$. The elution was with five column volumes of chloroform, acetone/methanol 98:2, 9:1, and 1:1 (vol/vol) and methanol, respectively. Ab of GBS patients' serum primarily bound lipid in this last acetone/methanol 1:1 fraction, designated 8A.

Liposome preparation. Each lipid fraction was used to make liposomes as previously described (36). Briefly, $100 \mu \mathrm{g}$, dry weight, of fractions 1 through 5 , and $50 \mu \mathrm{g}$ of fractions 6 through $9 \mathrm{~d}$ were each solubilized in chloroform methanol (2:1), and combined with $4 \mu \mathrm{mol}$ of egg lecithin and $3 \mu \mathrm{mol}$ of cholesterol. The lipids suspended in a total volume of $500 \mu \mathrm{l}$ were dried in a conical glass tube while rotating the tube in order to make a thin lipid film on the wall of the tube $\mathrm{DGVB}^{2+}$ and acid washed glass beads were added to the tubes and vortexed vigorously. The liposomes were washed by centrifugation in a Sorvall microfuge after the addition of $1 \mathrm{ml}$ of $\mathrm{GVB}^{2+}$ and resuspended in $1 \mathrm{ml} \mathrm{GVB}{ }^{2+} .20 \mu$ l of each liposome preparation was used in the $\mathrm{Cl}$ fixation and transfer assay for detection of $\mathrm{Ab}$ binding. The control liposomes contained egg lecithin and cholesterol.

Detection of antibody binding to lipids on thin layer chromatography plates. Lipids were applied to Merck HPTLC aluminum backed silica gel 60 plates (Applied Analytical Industries, Wilmington, NC), and separated with a solvent system made of chloroform/methanol/ $0.25 \% \mathrm{CaCl}_{2}, 5: 4: 1$ (vol/vol/vol). The front was allowed to migrate 9 $\mathrm{cm}$ from the origin. The plates were dried, soaked for $45 \mathrm{~s}$ in $0.05 \%$ poly isobutylmethacrylate (Polysciences, Inc., Warrington, PA) in $n$ hexane and allowed to dry. The plates were first incubated with $1 \%$ BSA in BSA/PBS for $3 \mathrm{~h}$ at $4^{\circ} \mathrm{C}$ and then with appropriately diluted GBS patient or control serum diluted in BSA/PBS overnight at $4^{\circ} \mathrm{C}$. The plates were washed seven times by immersion in $20 \mathrm{ml}$ of PBS for $1 \mathrm{~min}$. Binding of $\mathrm{Ab}$ was detected by incubating the plate for $2 \mathrm{~h}$ at $4^{\circ} \mathrm{C}$ with a peroxidase-labeled goat IgG against the $\mu$-chain of human IgM (Organon Teknika, Malvern, PA) diluted 1:1,000 in BSA/PBS. The plate was again washed six to seven times. Binding of peroxidaselabeled $\mathrm{Ab}$ was detected with a reagent containing 4-chloro-1-naphthol (Bio-Rad Laboratories, Richmond, CA) and hydrogen peroxide as previously described (37). Color was allowed to develop for 5-20 min and the reaction stopped by washing three times with PBS.

\section{Results}

C1 fixation by GBS serum Ab to PNM and pronase-treated $P N M$. Dose-response curves generated by incubating the PNM with varying amounts of serum from two selected GBS patients are shown in Fig. 1. Cl fixation is indicated by the lysis of the $1.5 \times 10^{7}$ EAC43 cells as described $(5,6)$. Since the lysis of erythrocytes in this assay directly reflects the fixation of a single limiting complement component, $\mathrm{C} 1$, the lysis curves are monotonic rising straight from the origin (38-41). Both GBS patients in Fig. 1 have a similar Ab titer, as determined by the initial slope of the dose response curve. The lipid nature of these antigen(s) was suggested since as seen in Fig. 1, GBS serum retained a substantial amount of reactivity to pronase treated PNM even though $>90 \%$ of the myelin protein was destroyed enzymatically. No specific fixation was noted in control serum against either the native or modified PNM antigen.

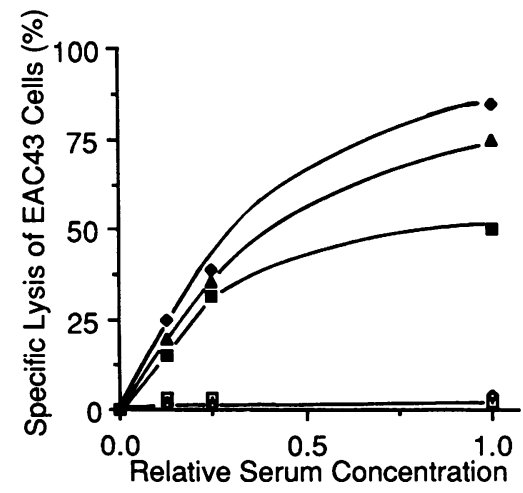

Figure 1. GBS patient serum $\mathrm{Ab}$ binds native and protease treated PNM. A fixed amount of native PNM was incubated with varying amounts of two different acute-phase GBS serum and bound increasing amounts of $\mathrm{Cl}$ in a dose dependent manner as shown by the lysis of EAC43 indicator cells $(\bullet \Delta)$. Serum of GBS patient ( $\mathbf{\Delta})$ continued to show significant binding to pronase treated myelin $(\square)$ and suggests that at least a portion of serum anti-PNM Ab binds a lipid component of PNM. Control serum did not show specific binding to either native $(\diamond)$ or pronase-treated PNM ( $\square$ ). The relative serum concentration of 1 equals a 1 to 10 dilution of test serum. 
Anti-PNM Ab binding to lipid fractions reincorporated into liposomes. To determine which class of myelin lipid is bound by anti-PNM Ab, GBS serum was screened for reactivity to lipids fractionated on the basis of partitioning and solubility and reincorporated into artificial lipid membranes of egg lecithin and cholesterol. As seen in Fig. 2, specific Ab binding detected by lysis of EAC43 cells was greatest in liposomes made with fraction 8 . Some binding was also noted with fractions 3, and to an even lesser extent fraction 4. No significant binding above that to control liposomes was noted for other lipid fractions in the series of three patient sera screened in this manner including 9a-d, which contained PNM gangliosides.

Antiphosphorylcholine $\mathrm{Ab}$ activity detected by $\mathrm{Cl}$ fixation to control liposomes by each serum (42) was subtracted from the total $\mathrm{Cl}$ binding to liposomes containing additional lipid to obtain the specific Ab activity.

Titers of complement fixing Ab to fraction 8A neutral glycolipids (NGL) were determined in 10 GBS patients. Fraction $8 \mathrm{~A}$ was further purified from fraction 8 (see methods). Titers in all acute-phase GBS patients studied were significantly elevated $(50-220 \mathrm{U} / \mathrm{ml})$ over six disease controls $(0-5 \mathrm{U} / \mathrm{ml})$ and 9 normals (0-6 U/ml) (Fig. 3). Disease controls included two patients with systemic lupus erythematosus, one with rheumatoid arthritis, one with brachial plexopathy, and one with sarcoidosis. In 3 of 10 GBS patients, the anti-NGL Ab titers were much lower than their anti-PNM Ab titer. To determine the relationship between anti-NGL $A b$ and anti-PNM $A b$ in these patients, two different GBS sera, one whose anti-NGL titer correlated well with the anti-PNM Ab titer and one that did not, were absorbed three times overnight at $4^{\circ} \mathrm{C}$ with either an equal volume of pelleted NGL-liposomes (fraction 8A) or control liposomes and the residual anti-PNM Ab titer determined. As seen in Fig. 4, absorption by NGL-liposomes resulted in the loss of $85 \%$ of the anti-PNM Ab activity from the GBS serum in which both Ab titers correlated, but only $20 \%$ of anti-PNM Ab activity could be absorbed when the two Ab titers correlated poorly.

Detection of specific lipid bound by Ab of GBS serum. To further identify the lipid or lipids that Ab in GBS serum binds, serum from 8 patients and 10 controls was incubated with

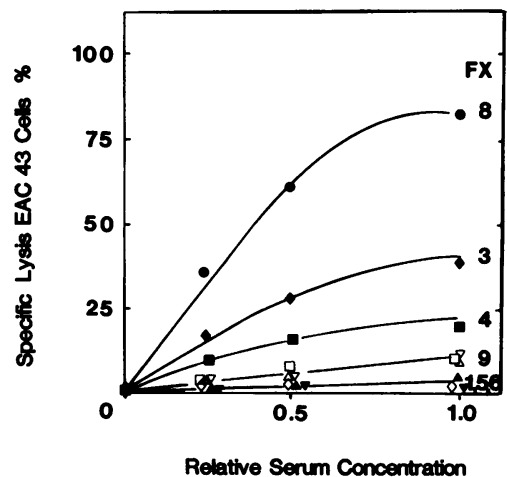

Figure 2. Ab in GBS serum binds to liposomes prepared with lipid fractions of human PNM. Varying dilutions of a GBS serum were incubated with liposomes containing 50 to $100 \mu \mathrm{g}$, dry weight, of each lipid fraction and $4 \mu \mathrm{mol}$ of egg lecithin and $3 \mu \mathrm{mol}$ cholesterol. Binding of $\mathrm{Ab}$, detected by specific $\mathrm{Cl}$ fixation, was most effective to

fraction $8(\bullet)$ which contained neutral glycolipids with four to six carbohydrates. $\mathrm{Cl}$ fixation was also noted to liposome containing fraction $3(\bullet)$ and $4(0)$. The relative serum concentration of 1 equals a 1 to 12.5 dilution of test serum.

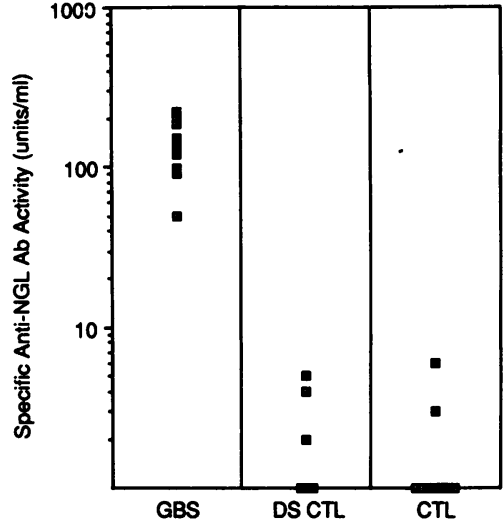

Figure 3. Anti-NGL Ab activity in serum of GBS patients and controls. The titers of antiNGL (fraction 8A) Ab activity, expressed as a log are reported as units/milliliter (i.e., 100 $\mathrm{U} / \mathrm{ml}$ represents that a $1 / 100$ dilution of serum will activate enough $\mathrm{Cl}$ to lyse $30 \%$ of EAC43 indicator cells) in this compound figure. AntiNGL $A b$ titers for 10 acute-phase GBS pa-

tients are shown in the left hand column and are significantly elevated over those of 9 healthy individuals (CTL) and 6 patients with various diseases (DS CTL) including SLE, sarcoidosis, brachial plexitis, diabetes, and alcoholism.

fraction 8A lipids separated on thin-layer chromatography plates. Ab binding was detected with peroxidase-labeled goat anti-human IgM ( $\mu$-chain specific). In six of the eight GBS patients studied in this manner, significant binding of IgM over control was found to a single minor lipid band of fraction 8A migrating just anterior to neolactohexaosyl (nLcOse ${ }_{6}$ ) ceramide but significantly behind paragloboside (Fig. 5). In four GBS patients examined no significant binding was seen to any of the PNM gangliosides run in parallel (data not shown). Some fainter binding was also noted to some rapidly migrating unidentified lipid bands contaminating the crude ganglioside fraction. No significant staining was seen with control serum (Fig. 5). Incubation of a single GBS patient's plasma with extracts of human and dog sciatic nerve as well as a series of neutral and acidic glycolipids standards (Fig. 6) showed binding of IgM, primarily, to single glycolipid bands in both dog and human nerve. Although migration of these two bands were similar, the $\boldsymbol{R}_{\mathrm{f}}$ of the human band was slightly slower suggesting some possible differences between the two molecules. With lower dilutions of the primary $(<100$-fold $)$ and

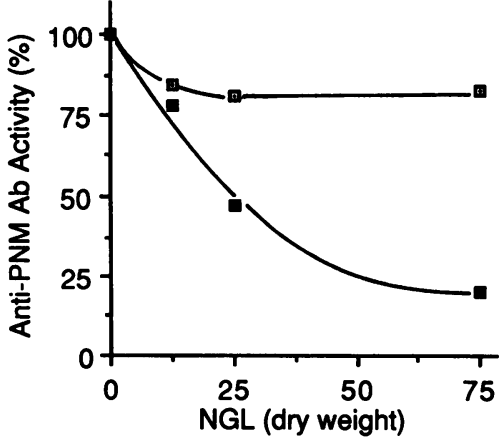

weight, fraction $8 \mathrm{~A}$ (see text), $4 \mu \mathrm{mol}$ of egg lecithin and $3 \mu \mathrm{mol}$ cholesterol or lecithin and cholesterol alone. Percent loss of anti-PNM $\mathrm{Ab}$ activity was calculated on the basis of the anti-PNM Ab activity of the same serum during serial absorption with control liposomes, as $100 \%$. Only $20 \%$ of Ab activity could be depleted in one serum (a) while most of the anti-PNM Ab activity was depleted in the second GBS serum ( $\square$ ). 


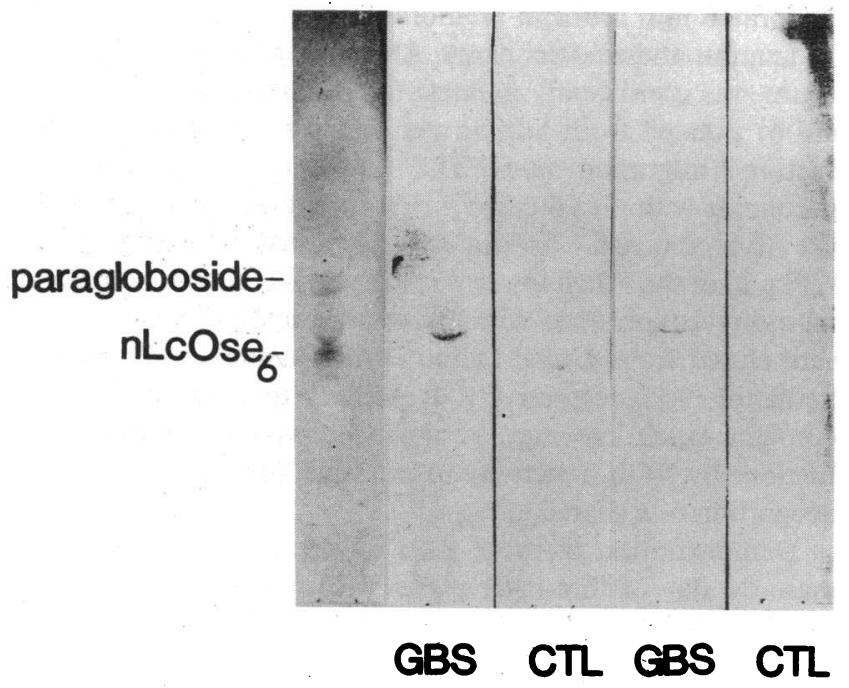

Figure 5. IgM Ab of GBS serum binds an orcinol positive band of lipid fraction $8 \mathrm{~A}$ from human nerve separated on HPTLC plates. Either $20 \mu \mathrm{g}$ (left lane) or $15 \mu \mathrm{g}$, dry weight of fraction $8 \mathrm{~A}$ was separated on HPTLC plates as described in text. The glycolipid bands in the far left hand column were detected with orcinol. Other lanes were incubated with 100-fold and 200-fold dilution of either GBS (from left to right, lane 2 and 4, respectively) or CTL (lane 3 and 5 , respectively) serum. Binding to a single band in fraction $8 \mathrm{~A}$ by GBS serum was detected with a peroxidase labeled goat IgG to human IgM, $\mu$-chain specific. No significant staining was seen with control serum.

secondary $\mathrm{Ab}$ ( $<1,000$-fold) faint staining of multiple other lipids bands could be seen. Since this binding was easily diluted out and was not further augmented by increasing the

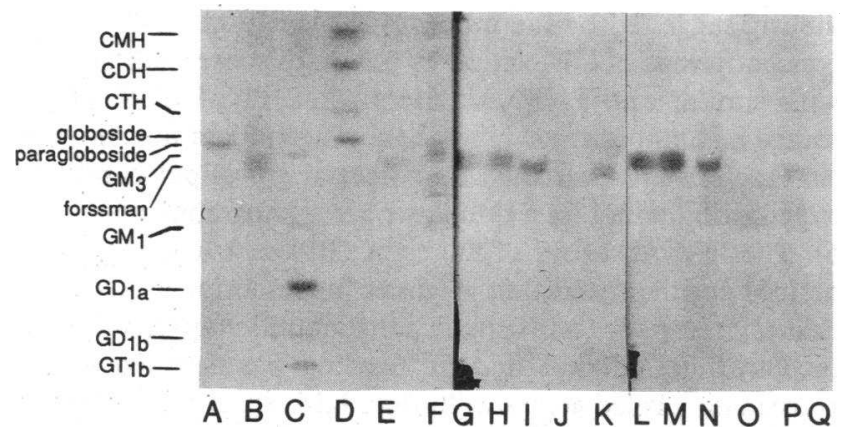

Figure 6. GBS IgM binds similar lipids in both human and dog sciatic nerve. A single GBS plasma was used for immunoblotting the glycolipids separated on two HPTLC plates. Lanes $G, H, L$, and $M$, contained Forssman glycolipid from dog sciatic nerve (G and L, 0.12 $\mu \mathrm{g} ; H$ and $M, 0.24 \mu \mathrm{g}) ; I$ and $N$, fraction 8 from dog sciatic nerve ( $\sim 2 \& 1 \mu \mathrm{g}$ total lipids, respectively); $J$, neutral glycolipids from human erythrocytes ( $\sim 1.5 \mu \mathrm{g}$ total lipids); $K$ and $P$, fraction 8 from human sciatic nerve ( $\sim 3$ and $1.5 \mu \mathrm{g}$ total lipids, respectively); 0 , bovine brain gangliosides (4.0 $\mu \mathrm{g}$ total); $Q$, paragloboside $(0.2 \mu \mathrm{g})$. Plasma dilution from lanes $G-K$ was 100 -fold and for lanes $L-Q$ it was 75 -fold. Glycolipids in lanes $A-E$ were detected by orcinol spray. Lane $A$, paraglobside ( $0.5 \mu \mathrm{g}) ; B$, fraction 8 from $\operatorname{dog}$ sciatic nerve ( $3 \mu \mathrm{g}) ; C$, bovine brain gangliosides $(10 \mu \mathrm{g}) ; D$, neutral glycolipid standards ( $3.5 \mu \mathrm{g}) ; E$, Forssman glycolipid from dog sciatic nerve $(\sim 0.6 \mu \mathrm{g})$ and $F$, fraction 8 from human sciatic nerve $(\sim 4 \mu \mathrm{g})$. GBS IgM bound primarily to Forssman glycolipid from dog sciatic nerve and a similar lipid in fraction 8 prepared from dog and human nerves.

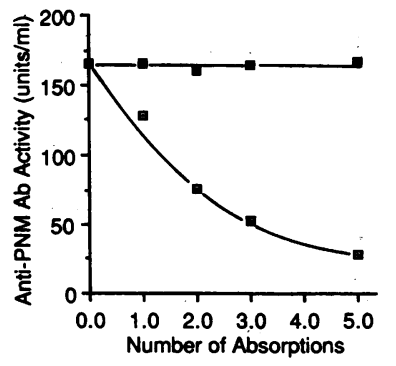

Figure 7. Loss of anti-PNM Ab from GBS serum following serial absorption with liposomes containing Forssman antigen. A GBS patient serum was absorbed with liposomes containing either $25 \mu \mathrm{g}$ Forssman hapten, $4 \mu \mathrm{mol}$ of egg lecithin, $3 \mu \mathrm{mol}$ of cholesterol ( $\square$ ) or lecithin and cholesterol alone (i). Only absorptions with Forssman lipid containing liposomes

resulted in significant loss of anti-PNM Ab activity in a dose-dependent manner.

concentration of the lipid band, it was not considered to be specific.

Absorption of anti-PNM and anti-NGL Ab with Forssman and control liposomes. Serial overnight absorptions of one of eight GBS patients' serum with aliquots of liposomes containing either $25 \mu \mathrm{g}$ dry weight of Forssman lipid purified from sheep erythrocytes, $4 \mu \mathrm{mol}$ of egg lecithin and $3 \mu \mathrm{mol}$ of cholesterol or lecithin and cholesterol without glycolipid are shown in Fig. 7. Absorption by Forssman-liposomes resulted in the loss of $83 \%$ of anti-PNM Ab activity and $100 \%$ of antiNGL activity (Table I) while absorption by control liposomes did not significantly alter the anti-PNM Ab titer. In seven other GBS sera $18-97 \%$ of anti-PNM Ab activity and $80-100 \%$ of anti-NGL activity was absorbed by Forssman-liposomes (Table I).

Detection of GBS and control serum Ab binding to Forssman-liposomes by $\mathrm{Cl}$ fixation. Ab binding to Forssman antigen isolated from sheep erythrocytes and reincorporated into artificial lipid bilayers is shown in Fig. 8. In all 12 GBS sera studied titers of anti-Forssman $\mathrm{Ab}(54$ and $272 \mathrm{U} / \mathrm{ml}$ ) were significantly elevated over 12 disease controls ( 0 to $22 \mathrm{U} / \mathrm{ml}$ ),

Table I. Antibody Activity (U/ml)*

\begin{tabular}{|c|c|c|c|c|c|}
\hline \multirow[b]{2}{*}{ GBS } & \multicolumn{3}{|c|}{ Pre-Forssman absorption } & \multicolumn{2}{|c|}{$\begin{array}{l}\text { Post-Forssman } \\
\text { absorption }\end{array}$} \\
\hline & $\begin{array}{c}\text { Anti- } \\
\text { PNM Ab }\end{array}$ & $\begin{array}{c}\text { Anti- } \\
\text { NGL Ab }\end{array}$ & $\begin{array}{c}\text { Anti- } \\
\text { Forssman Ab }\end{array}$ & $\begin{array}{c}\text { Anti- } \\
\text { PNM Ab }\end{array}$ & $\begin{array}{c}\text { Anti- } \\
\text { NGL Ab }\end{array}$ \\
\hline $1^{\$ \S * * *}$ & 160 & 208 & 210 & 24 & 0 \\
\hline $2^{\S}$ & 80 & 91 & 90 & ND & ND \\
\hline $3^{\text {*1 }}$ & 348 & 50 & 54 & 289 & 0 \\
\hline $4^{\S}$ & 250 & 97 & 121 & ND & ND \\
\hline $5^{* *}$ & 117 & 150 & 143 & ND & ND \\
\hline $6^{\S}$ & 88 & 98 & 100 & 3 & 4 \\
\hline $7^{8}$ & 358 & 188 & 196 & 235 & 26 \\
\hline $8^{\delta * *}$ & 100 & 120 & 115 & 28 & 0 \\
\hline 9 & 142 & 136 & 149 & 28 & 0 \\
\hline 10 & 222 & 220 & 272 & 58 & 25 \\
\hline 11 & 66 & ND & 105 & ND & ND \\
\hline $12^{1}$ & 61 & 60 & 57 & 18 & 0 \\
\hline
\end{tabular}

* Detected by $\mathrm{Cl}$ fixation and transfer assay.

‡ Absorbed with NGL-fraction 8A, Fig. 4.

${ }^{8}$ Positive binding to NGL on HPTLC plates.

' Negative binding to NGL on HPTLC plates.

** Screened against fractionated lipids of PNM. 
and 25 control sera from normal laboratory workers ( 0 to 11 $\mathrm{U} / \mathrm{ml}$ ). Disease controls included patients with systemic lupus erythematosus, rheumatoid arthritis, diabetic neuropathy, multiple sclerosis, transverse myelitis, poliomyelitis, and amyotropic lateral sclerosis. The anti-Forssman Ab titers in serum of GBS patients, in general, correlated with their antiNGL titers (Table I) and decreased over time, in a manner similar to the fall in anti-PNM Ab. Two of the disease controls (anti-Forssman titers, 20 and $22 \mathrm{U} / \mathrm{ml}$ ) were significantly higher than anti-NGL Ab titers ( 0 and $4 \mathrm{U} / \mathrm{ml}$, respectively).

Binding of a monoclonal $A b$ against Forssman antigen to $a$ NGL of human peripheral nerve. A rat hybridoma IgM Ab, MI/87.27.7 (ATCC), specific for Forssman antigen (43) bound both Forssman glycolipid, purified from sheep erythrocytes and a single band of the NGL fraction, 8A of human PNM separated on HPTLC plates (Fig. 9) but not a series of neutral and acidic glycolipids. Binding was similar to that of IgM serum Ab of GBS patients (Figs. 5 and 6). No binding was seen in the absence of primary $\mathrm{Ab}$ or with a rat IgM monoclonal $\mathrm{Ab}$ without specificity for sheep erythrocyte Forssman.

\section{Discussion}

Anti-PNM Ab in GBS serum binds human PNM and activates complement, thus generating C5b-9 presumably one of the effectors in peripheral nerve demyelination (7-9). Previous studies did not show in a consistent manner antibodies to any PNM component $(27,28)$, even though both proteins and lipids known to induce inflammatory demyelination in experimental animals such as $P_{2}$ and galactocerebroside $(18,19)$ were included as antigens. In view of the finding that complement fixing $\mathrm{Ab}$ that react to normal PNM are consistently present in acute-phase GBS serum $(5,6)$, we wanted to know the specific antigen(s) of PNM that these anti-PNM Ab reacted to, as well as the heterogeneity of their reactivity.

As shown in Fig. 1, the $\mathrm{Cl}$ fixing capacity of the anti-PNM $\mathrm{Ab}$ activities in GBS serum were remarkably preserved even though $>90 \%$ of protein in PNM was removed by pronase treatment. These results suggested that at least one of the myelin antigens was protease resistant and possibly a lipid. The lipid nature of the antigen(s) was further explored by use of liposomes made of fractionated lipid extracts of PNM, rein-

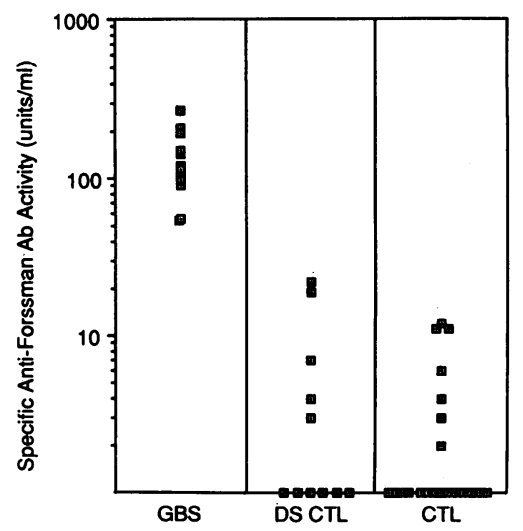

Figure 8. Specific antiForssman $\mathrm{Ab}$ activity in serum of GBS patients and controls. Titers of specific anti-Forssman Ab activity are expressed as a log. Those titers for 12 GBS patients in the far left hand column are significantly elevated over 11 disease controls (DS CTL) and 25 healthy laboratory workers (CTL). Disease controls included patients with

multiple sclerosis, amyotrophic lateral sclerosis, SLE, rheumatoid arthritis, poliomyelitis, and diabetic neuropathy. corporated into artificial membranes as antigen targets in the $\mathrm{C} 1$ fixation and transfer assay. Ab binding from GBS patient serum was consistently greatest to lipid fraction 8A (Figs. 5 and 6) isolated from human peripheral nerve. Based on the fraction's migration on HPTLC plates, it contained neutral glycolipids with 4 to 6 carbohydrate residues. Lower but definite $\mathrm{Ab}$-mediated $\mathrm{Cl}$ fixation was also noted to fractions 3 and 4 (Fig. 2) of the Folch lower phase lipids which also contained neutral glycolipids but with fewer carbohydrate residues and were eluted from Unisil column with acetone and acetone/ methanol (9:1), respectively. Reactivity to fraction 3 and 4 although much. less may be due to cross-contamination of fractions by NGL, reactivity to multiple antigens, or possible recognition of a shared epitope.

Demonstration of more than one reactivity on the solid phase overlay of thin-layer plates with two of four GBS patients' sera (data not shown) would suggest one of the latter two possibilities.

As shown in Fig. 3, all 10 GBS patient sera screened showed significant $\mathrm{Ab}$-mediated $\mathrm{Cl}$ fixation to fraction $8 \mathrm{~A}$ neutral glycolipids reincorporated into liposomes. Titers of GBS patients varied between 50 and $220 \mathrm{U} / \mathrm{ml}$ and were significantly elevated over six disease controls $(0-5 \mathrm{U} / \mathrm{ml})$ and nine normal controls $(0-6 \mathrm{U} / \mathrm{ml})$. In the sera of 3 of $10 \mathrm{GBS}$ patients, titers against the neutral glycolipid fraction appeared to be significantly lower when compared to the total anti-PNM $\mathrm{Ab}$ titers (Table I). Absorption by fraction 8A-liposomes of serum of one of these three (Fig. 4) resulted in the loss of only $20 \%$ of the anti-PNM Ab activity which contrasted sharply with the near complete absorption of a second GBS serum anti-PNM Ab. This data suggested that anti-PNM Ab of some GBS patients recognize more than one antigen of PNM, one of which was contained in fraction $8 \AA$. Multiple or different antigens, with different densities on the myelin surface was previously suggested by the more rapid plateau at higher serum concentrations of $\mathrm{Cl}$ fixation by serum of some GBS patients with similar anti-PNM Ab titers when PNM of the same source and amount was used as an antigen (data not shown).

Fraction 8A contained four neutral glycolipid bands detected with orcinol on a thin layer chromatography plate (Fig. 5). The IgM Ab of six of the eight GBS sera bound a single orcinol positive band that migrates just anterior to neolactohexaosylceremide, but behind paragloboside containing four carbohydrates (Figs. 5 and 6). Binding was detected with a peroxidase-labeled goat anti-human IgM Ab, $\mu$-chain specific. Some faint but definite $\mathrm{Ab}$ binding to this same band was also seen with 3 of 10 normal controls on the solid phase overlay but was significantly less than that seen with the GBS patients.

Binding of IgM from a GBS patient could also be detected to similar glycolipid, Forssman antigen isolated from dog sciatic nerve (Fig. 7) and sheep red blood cells (data not shown) but not a variety of other neutral and acidic glycolipids. Interestingly, titers of complement fixing $\mathrm{Ab}$ to Forssman antigen in GBS serum were significantly elevated over normal and disease controls (Fig. 8). Antigenic cross reactivity between NGL of fraction 8A, Forssman and human PNM was suggested by similar absorptions of serums of $8 \mathrm{GBS}$ patients with liposomes containing Forssman purified from sheep erythrocytes (Fig. 7, Table I). These absorptions resulted in the loss of $86-100 \%$ of anti-NGL Ab activity and $17-97 \%$ of anti-PNM $\mathrm{Ab}$ activity. No similar activity losses were seen with absorptions by control liposome alone (Fig. 7). Antigenic cross-reac- 
tivity was further suggested by binding of a monoclonal $\mathrm{Ab}$ specific for Forssman hapten (43) to a band of lipid fraction 8A of human nerve on a HPTLC plate (Fig. 9).

Forssman antigen is widely distributed in nature being a component of several viruses, bacteria, parasites, and the cell membranes of certain mammalian species including rodents, cats, sheep, and $\operatorname{dog}(44)$. Although the human species is generally considered to be Forssman negative, Forssman antigen was identified by $\mathrm{Ab}$ binding in the gastrointestinal mucosa of $30 \%$ of patients and in certain human tumors of the intestine, lung, and skin (44-47). Data of our absorption experiments suggest that Forssman or a cross-reacting glycolipid is a component of human PNM and that $\mathrm{Ab}$ to this myelin component is a portion in some and the primary component in other patients of the anti-PNM Ab that correlates with the development of peripheral nerve demyelination in $\operatorname{GBS}(5,6)$. Differences in mobility on chromatographic plates (Fig. 7) and lack of correlation between $\mathrm{Ab}$ titers to the myelin neutral glycolipid and Forssman antigen in some disease control serum suggested the antigenic structures of these two lipids were not completely identical.

$\mathrm{Ab}$ to Forssman antigen are part of heterophile responses that represent a series of cross-reacting antibodies that can frequently recognize carbohydrate determinants (44). Serum heterogenic antibodies including Forssman are reported to occur in $30-66 \%$ of normal humans but at generally lower serum concentrations than we are reporting $(47,48)$. Heterophile $\mathrm{Ab}$ are elevated in humans with infectious mononucleosis, certain viral and bacterial infections, juvenile rheumatoid arthritis and in some cases with liver diseases (44). In addition,

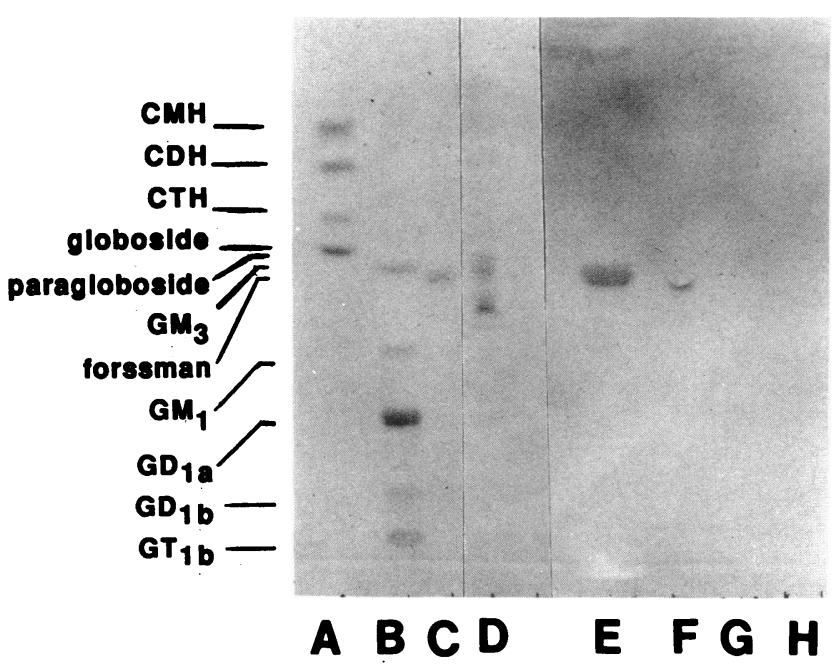

Figure 9. Anti-Forssman monoclonal Ab binds a NGL of human peripheral nerve. Tissue culture supernates of a rat hybridoma, secreting an IgM Ab specific for Forssman hapten (43) was used for immunoblotting glycolipids separated on HPTLC plates. Lanes $C$ and $E$ contained Forssman glycolipid from sheep erythrocytes (1.0 $\mu \mathrm{g}) ; D$ and $F$, fraction 8A from human sciatic nerve ( $\sim 3.0 \mu \mathrm{g}$ total lipid); $A$ and $H$, neutral glycolipid from human erythrocytes $(\sim 1.5 \mu \mathrm{g}$ total lipid); $B$ and $G$, bovine brain gangliosides ( $\sim 4.0 \mu \mathrm{g}$ total lipid). Lanes $E-H$ were incubated with $\mathrm{MI} / 87.27 .7$ hybridoma tissue culture fluid diluted one to four parts in 1\% BSA in PBS. Glycolipids on lanes $A-D$ were detected with an orcinol spray. The MAb bound to Forssman glycolipid from sheep erythrocytes and a similar migrating lipid band in fraction $8 \mathrm{~A}$ of human peripheral nerve. normal human spleen cells obtained at surgery when fused with mouse myeloma cells produced IgM or IgG Ab with specificity for the two terminal galactosamines of Forssman (49). Relatively high titers of anti-Forssman $\mathrm{Ab}$ were reported in normal individuals using a liposome, marker release assay without consideration of the background release, by serum, of marker from liposomes without the glycolipid (48). In the current study, $24 \%$ of 25 normal laboratory workers had measurable titers of anti-Forssman $\mathrm{Ab}$ which varied from 0 to 11 $\mathrm{U} / \mathrm{ml}$ (Fig. 8).

Forssman $\mathrm{Ab}$ responses are associated with disease production of an arthus response in guinea pig (50) and in a single patient with Waldenstrom's macroglobulinemia and IgM monoclonal gammopathy (51). Patients with Waldenstrom's macroglobulinemia frequently have peripheral neuropathy and IgM is described deposited on the myelin sheaths of their peripheral nerves (52-54). Anti-Forssman Ab in GBS patients may represent part of a humoral immune response to Forssman carbohydrate antigens, a common antigenic component present on a variety of viruses, bacteria, and other infectious agents that can participate in demyelination by binding to a cross-reacting epitope(s) of PNM NGL. It is apparent that anti-Forssman $\mathrm{Ab}$ can be detected in $24 \%$ of normal patients (Fig. 8) and are not associated with a subacute demyelinating neuropathy. Damage of the blood-nerve barrier would allow penetration of high molecular weight components such as IgM and $\mathrm{Cl}$, which would not occur under normal conditions (55). Recent experiments demonstrated that the $\mathrm{T}$ cell-mediated disease, EAE in rats resulted in classic demyelination of the $\mathrm{CNS}$ when a monoclonal $\mathrm{Ab}$ to an oligodendrocyte-associated glycoprotein was injected systemically (56). A similar synergism would also be an attractive hypothesis for demyelination of the peripheral nervous system.

Our studies suggest that an IgM Ab that could be triggered by multiple infectious agents in GBS patients, can bind to surface determinant of a Forssman-like lipid of human PNM and after penetration of a damage blood-nerve barrier, participate in the demyelination of peripheral nerve through activation of complement.

\section{Acknowledgments}

We thank Dr. M. L. Shin for review of the manuscript, as well as Howard Cobb and Jehangir Jungalwala for their technical assistance for some parts of this project.

Supported by the National Institutes of Health grants 2 POI NS20022 and POI NS22849 to C. L. Koski and U. S. Public Health Service grants HD 05515 and NS 24405 to F. B. Jungalwala.

\section{References}

1. Arnason, B. G. W. 1984. Acute inflammatory demyelinating polyradiculoneuropathies. In Peripheral Neuropathy. P. J. Dyck, P. K. Thomas, E. H. Lambert, and R. Bunge, editors. W. B. Saunders Co., Philadelphia, PA. 2050-2100.

2. Koski, C. L. 1984. Guillain-Barre Syndrome. Neurol. Clin. 2:355-366

3. Melnick, S. C. 1963. Thirty-eight cases of the Guillain-Barre' Syndrome: an immunological study. Br. Med. J. 1:368-373.

4. Latov, N., R. B. Gross, J. Kastelman, T. Flanagan, S. Lamme, D. A. Alkaitis, M. R. Olarte, W. H. Sherman, L. Chess, and A. S. Penn. 
1981. Complement fixing antiperipheral nerve myelin antibodies in patients with inflammatory polyneuritis and with polyneuropathy and paraproteinemia. Neurology. 31:1530-1534.

5. Koski, C. L., R. Humphrey, and M. L. Shin. 1985. Anti-peripheral myelin antibody in patients with demyelinating neuropathy: quantitative and kinetic determination of serum antibody by complement component 1 fixation. Proc. Natl. Acad. Sci. USA. 82:905-909.

6. Koski, C. L., E. Gratz, J. Sutherland, and R. F. Mayer. 1986. Clinical correlation with anti-peripheral myelin antibodies in Guillain-Barre-Syndrome. Ann. Neurol. 19:573-577.

7. Sanders, M. E., C. L. Koski, D. Robbins, M. L. Shin, M. M. Frank, and K. A. Joiner. 1986. Activated terminal complement in cerebrospinal fluid in Guillain-Barre syndrome and multiple sclerosis. J. Immunol. 136:4456-4459.

8. Hartung, H. P., C. Schwenke, D. Bitter-Suermann, and K. V. Toyka. 1987. Guillain-Barre Syndrome: activated complement components C3a, C5a in CSF. Neurology. 37:1006-1009.

9. Koski, C. L., M. E. Sanders, P. T. Swoveland, T. S. Lawley, M. L. Shin, M. M. Frank, and K. A. Joiner. 1987. Activation of terminal components of complement in patients with Guillain-Barre Syndrome and other demyelinating neuropathies. J. Clin. Invest. 80:1492-1497.

10. Osterman, P. O., J. Faguis, G. Lundermo, P. Pihlstedt, R. Pirskanen, A. Siden, and J. Safwenberg. 1984. Beneficial effects of plasma exchange in acute inflammatory polyradiculoneuropathy. Lancet. ii:1296-1298.

11. Guillain-Barre Study Group. 1985. Plasmapheresis of acute Guillain-Barre Syndrome. Neurology. 35:1096-1104.

12. Cooperative French Group. 1984. Cooperative randomized trial of plasma exchange (P.E.) in Guillain-Barre Syndrome (GBS): preliminary results. Ann. Med. Interne (Paris). 135:8.

13. Latov, N., W. H. Sherman, R. Nemni, G. Galassi, J. S. Shyong, A. S. Penn, L. Chess, M. K. Olatre, L. P. Rowland, and E. F. Osserman. 1980. Plasma cell dyscrasia and peripheral neuropathy with a monoclonal antibody to peripheral nerve myelin. $N$. Engl. J. Med. 303:618-621.

14. Ilyas, A. A., R. H. Quarles, T. D. Macintosh, M. J. Dobersen, B. D. Trapp, M. C. Dalakas, and R. O. Brady. 1984. IgM in a human neuropathy related to paraproteinemia binds to a carbohydrate determinant in the myelin-associated glycoprotein and to a ganglioside. Proc. Natl. Acad. Sci. USA. 81:1225-1229.

15. Nobile-Orazio, E., A. P. Hays, N. Latov, G. Pernan, J. Golier, M. E. Shy, and L. Freddo. 1984. Specificity of mouse and human monoclonal antibodies to myelin-associated glycoprotein. Neurology. 34:1336-1342.

16. Chou, D. K. H., A. A. Ilyas, J. E. Evans, C. Costello, R. H. Quarles, and F. B. Jungalwala. 1986. Structure of sulfated glucuronyl glycolipids in the nervous system reacting with HNK-1 antibody and some IgM paraproteins in neuropathy. J. Biol. Chem. 261:1171711725.

17. Hays, A. P., N. Latov, M. Takatsu, and W. H. Sherman. 1987. Experimental demyelination of nerve induced by serum of patients with neuropathy and an anti-MAG M-protein. Neurology. 37:242246.

18. Brostoff, S. W., S. Levitt, and J. N. Powers. 1977. Induction of experimental allergic neuritis with a peptide from myelin $\mathbf{P}_{\mathbf{2}}$ basic protein. Nature (Lond.). 268:752-753.

19. Saida, T., K. Saida, S. H. Dorfman, D. H. Silberberg, A. J. Sumner, M. L. Manning, R. P. Lisak, and M. J. Brown. 1979. Experimental allergic neuritis induced by sensitization with galactocerebroside. Science (Wash. DC). 204:1103-1 106.

20. Seil, F. J., M. W. Kies, and M. L. Bacon. 1981. A comparison of demyelinating and myelination-inhibiting factor induction by whole peripheral nerve tissue and $P_{2}$ protein. Brain Res. 210;441-448.

21. Saida, T., K. Saida, R. P. Lisak, M. J. Brown, D. H. Silberberg, and A. K. Asbury. 1982. In vivo demyelinating activity of serum from patients with Guillain-Barre Syndrome. Ann. Neurol. 11:69-75.

22. Saida, T., K. Saida, and D. H. Silberberg. 1979. Demyelination produced by experimental allergic neuritis serum and acute galacto- cerebroside anti-serum in CNS cultures. An ultrastructural study. Acta Neuropathol. 48:19-25.

23. Armati-Gulson, P. J., R. P. Lisak D. Kuchmy, and J. Pollard. 1983. ${ }^{51} \mathrm{Cr}$ release cytotoxicity radioimmunoassay to detect immune cytotoxic reactions to rat Schwann cells in vitro. Neurosci. Lett. 35:321-326.

24. Feasby, T. E., A. F. Hahn, and J. J. Gilbert. 1982. Passive transfer of demyelinating activity in Guillain-Barre polyneuropathy. Neurology. 32:1159-1167.

25. Sumner, A. J., R. P. Lisak, M. J. Brown, and A. K. Asbury. 1983. Demyelinating activity of Guillain-Barre Syndrome (GBS) serum. Neurology. 33;81. (Abstr.)

26. Dubois-Dalq, M., M. Buyse, G. Buyse, and F. Gorce. 1971. The action of Guillain-Barre Syndrome serum in myelin: A tissue culture and electron microscopic analysis. J. Neurol. Sci. 13:67-83.

27. Rostami, A. M., J. B. Burns, P. A. Eccleston, M. C. Manning, R. P. Lisak, and D. H. Silberberg. 1987. Search for antibodies to galactocerebroside in the serum and cerebrospinal fluid in human demyelinating disorders. Ann. Neurol. 22:381-383.

28. Hughs, R. A. C., and J. B. Winer. 1984. Guillain Barre Syndrome. In Recent Advances in Clinical Neurology. Churchill Livingstone, Edinburgh. 19-49.

29. Ilyas, A. A., H. J. Willison, R. H. Quarles, F. B. Jungalwala, D. R. Cornblath, B. D. Trapp, D. E. Griffen, J. W. Griffen, and G. M. McKhan. 1988. Serum antibodies to ganglioside in Guillain-Barre Syndrome. Ann. Neurol. 23:440-447.

30. Asbury, A., B. Arnason, H. Karp, and D. E. McFarlin. 1978. Criteria for the diagnosis of Guillain-Barre syndrome. Ann. Neurol. 3:565-566.

31. Kabat, E. A., and M. M. Mayer. 1964. Complement and complement fixation. In Experimental Immunochemistry. Charles C. Thomas, Publisher, Springfield, IL. 149-153.

32. Norton, W. T. 1975. Isolation of myelin from the nerve tissue. Methods Enzymol. 31:435-444.

33. Markwell, M. A. K., S. M. Haas, L. L. Bieber, and N. E. Tolbert. 1978. A modification of the Lowry procedure to simplify protein determination in membrane and lipoprotein samples. Anal. Biochem. 87:206-210.

34. Folch, J., M. Lees, and G. H. Sloane-Stanley. 1957. A simple method for the isolation and purification of total lipids from animal tissue. J. Biol. Chem. 226:497-509.

35. Williams, M. A., and R. H. McCluer. 1980. The use of Sep-Pak $\mathrm{C}_{18}$ cartridges during the isolation of gangliosides. $J$. Neurochem. 35:266-269.

36. Shin, M. L., W. A. Paznekas, A. S. Abramovitz, and M. M. Mayer. 1977. On the mechanism of membrane damage by C: exposure of hydrophobic sites on activated C proteins. J. Immunol. 119:13581364.

37. Chou, D. K. H., G. A. Schwartring, J. E. Evans, and F. B. Jungalwala. 1987. Sulfoglucuronyl-neolacto series of glycolipids in peripheral nerves reacting with HNK-1 antibody. J. Neurochem. 49:865-873.

38. Mayer, M. M. 1953. The mechanism of hemolysis by antibody and complement. Is immune hemolysis a single or multiple-hit process? Trans. Int. Congr. Microbiol. 2:151-157.

39. Borsos, T., H. J. Rapp, and M. M. Mayer. 1961. Studies on the second component of complement 1 . The reaction between EAC' 1,4 and C'2: evidence on the single site mechanism of immune hemolysis and determination of C'2 on a molecular basis. J. Immunol. 87:310325.

40. Borsos, T., H. R. Colton, J. S. Spalter, N. Rogentine, and H. J. Rapp. 1968. The C'la fixation and transfer test: examples of its applicability to the detection and enumeration of antigens and antibodies at cell surfaces. J. Immunol. 101:392-398.

41. Ramm, L. E., M. B. Whitlow, and M. M. Mayer. 1982. Transmembrane channel formation by complement: functional analysis of number of $\mathrm{C5b6}, \mathrm{C} 7, \mathrm{C} 8$, and $\mathrm{C} 9$ molecules required for a single channel. Proc. Natl. Acad. Sci. USA. 79:4751-4755. 
42. Alving, C. R. 1984. Natural antibodies against phospholipids and liposomes in humans. Biochem. Soc. Trans. 12:342-344.

43. Springer, T., G. Galfre, D. S. Secher, and C. Milstein. 1978. Monoclonal xenogeneic antibodies to murine cell surface antigens: identification of novel leukocyte differentiation antigens. Eur. J. Immunol. 8:539-551.

44. Kano, K., and F. Milgrom. 1977. Heterophile Antigens and antibodies in medicine. Curr. Top. Microbiol. Immunol. 77:43-69.

45. Hakomori, S., S. M. Wang, and W. W. Young. 1977. Isoantigenic expression of Forssman glycolipid in human gastric and colonic mucosa: its possible identity with A-like antigen in human cancer. Proc. Natl. Acad. Sci. USA. 74:3023-3027.

46. Taniquchi, N., N. Yokosawa, M. Narita, T. Mitsuyama, and A. Makita. 1981. Expression of Forssman antigen synthesis and degradation in human lung cancer. J. Natl. Cancer Inst. 67:577-583.

47. Levine, P. 1978. Blood group and tissue genetic markers in familial adenocarcinoma: potential specific immunotherapy. Semin. Oncol. 5:25-34.

48. Young, W. W., S. I. Hakomori, and P. Levine. 1979. Characterization of anti-Forssman (anti-Fs) antibodies in human sera: their specificity and possible changes in patients with cancer. J. Immunol. 123:92-96.

49. Nowinski, R., C. Berglund, J. Lane, M. Lostrum, I. Bernstein, W. Young, and S. I. Hakomori. 1980. Human monoclonal antibody against Forssman antigen. Science (Wash. DC). 210:537-539.

50. Baker, J. R., G. R. Bullock, K. D. Butler, I. H. Williamson, and
A. M. White. 1985. Ultrastructural analysis of the vascular damage in the lethal and sublethal anti-Forssman reaction in guinea pigs. $B r . J$. Exp. Pathol. 66:709-718.

51. Alving, C. R., K. C. Joseph, and R. Wistar. 1974. Influence of membrane composition on the interaction of a human monoclonal "anti-Forssman" immunoglobulin with liposomes. Biochemistry. 13:4818-4824.

52. Dellagi, K., J. C. Brouet, and F. Danon. 1979. Cross-idiotypic antigens among monoclonal immunoglobulin $\mathrm{M}$ from patients with Waldenstrom's macroglobulinemia and polyneuropathy. J. Clin. Invest. $64: 1530-1534$

53. Julien, J., C. Vital, J. M. Vallat, A. Laquency, C. Deminiere, and D. Darriet. 1978. Polyneuropathy in Waldenstrom's macroglobulinemia. Deposition of M component on myelin sheaths. Arch. Neurol. 35:423-425.

54. Propp, R. P., E. Means, R. Deibel, G. Sherer, and K. Barron. 1975. Waldenstrom's maglobulinemia and neuropathy: deposition of M component on myelin sheathes. Neurology. 25:980-988.

55. Steck, A. J., M. Norman, J. C. Justafre, C. Meier, K. V. Toyka, K. Heininger, and G. Stoll. 1985. Passive transfer studies in demyelinating neuropathy with IgM monoclonal antibodies to myelin-associated glycoprotein. J. Neurol. Neurosurg. Psychiatry. 48:927-929.

56. Schluesener, H. J., R. A. Sobel, C. Linington, and H. C. Weiner. 1987. A monoclonal antibody against myelin oligodendrocyte glycoprotein induces relapses and demyelination in central nervous system autoimmune disease. J. Immunol. 139:4016-4021. 